\title{
(6) OPEN ACCESS \\ Development of a new clinical decision rule for cervical CT to detect cervical spine injury in patients with head or neck trauma
}

\author{
Takeshi Inagaki, ${ }^{1}$ Akio Kimura, ${ }^{1}$ Go Makishi, ${ }^{2}$ Shigeru Tanaka, ${ }^{2}$ Noriko Tanaka ${ }^{3}$
}

\begin{abstract}
'Department of Emergency Medicine and Critical Care, Center Hospital of the National Center for Global Health and Medicine, Tokyo, Japan ${ }^{2}$ Department of Emergency and Critical Care Medicine, Seirei Hamamatsu General Hospital, Hamamatsu, Shizuoka, Japan ${ }^{3}$ Biostatistics Section, Department of Clinical Research and Informatics, Clinical Science Center, National Center for Global Health and Medicine, Tokyo, Japan
\end{abstract}

\section{Correspondence to}

Dr Takeshi Inagaki, Department of Emergency Medicine and

Critical Care, Center Hospital of the National Center for Global Health and Medicine, Tokyo, Japan;

tinagaki@hosp.ncgm.go.jp

Received 27 May 2017 Revised 10 June 2018 Accepted 21 June 2018 Published Online First 21 July 2018

\begin{abstract}
Objective Previous cervical spine imaging decision rules have been based on positive findings on plain X-ray and are limited by lack of specificity, age restrictions and complicated algorithms. We previously derived and validated a clinical decision rule (Rule 1) for detecting cervical spine injury (CSI) on CT in a single-centre study. This recommended CT for patients with (1) GCS score $<14$, (2) GCS 14-15 and posterior cervical tenderness or neurological deficit, (3) age $\geq 60$ years and fall down stairs, or (4) age <60 and injured in a motorcycle collision or fallen from height. This study assessed the accuracy and reliability of this rule and refined the rule.

Methods We conducted a prospective, dual-centre study at two Japanese EDs between August 2012 and March 2014. Patients with head or neck injury $\geq 16$ years of age were included. Clinical data were collected from medical records. Imaging was at the discretion of the treating physician. CSI was diagnosed as a fracture or dislocation seen on CT; patients who were not imaged were followed for 14 days. We analysed the sensitivity and specificity of Rule 1 and refined it post hoc using recursive partitioning.
\end{abstract}

Results 1192 patients were enrolled. 927 completed follow-up. Of these, 584 (63.0\%) underwent CT imaging and 38 had CSI. Sensitivity and specificity of Rule 1 were $92.1 \%(95 \% \mathrm{Cl} 79.2 \%$ to $97.3 \%)$ and $58.6 \%(95 \% \mathrm{Cl}$ $55.4 \%$ to $61.9 \%$ ). A second rule (Rule 2 ) was derived recommending $\mathrm{CT}$ for those with any of the following: GCS $<14$, cervical tenderness, neurological deficit or mechanism of injury (fall down stairs, motorcycle collision or fall from height) without age limits. Sensitivity and specificity were $100 \%$ (95\% Cl $90.8 \%$ to $100 \%)$ and $51.9 \%$ (95\% Cl $48.6 \%$ to $55.2 \%$ ), respectively. Conclusions Our initial CT decision rule had lower sensitivity than in our initial validation study. A refined decision rule based on GCS, neck tenderness, neurological deficit and mechanism of injury showed excellent sensitivity with a small loss of specificity. Rule 2 will now need validation in an independent cohort.

\section{INTRODUCTION}

\section{Background}

Cervical spine injury (CSI) occurs in 2\%-6\% of patients with blunt trauma to the head or neck. ${ }^{12}$ Most clinicians will investigate patients with cervical tenderness or neurological deficit using cervical radiographic assessment, but a non-negligible proportion of patients with cervical spine injury show neither tenderness nor neurological abnormality. ${ }^{3}$ Because overlooking CSI may lead to severe

\section{Key messages}

What is already known on this subject

- The Canadian C-spine rule and National Emergency X-radiography Utilisation Study low-risk criteria were validated more than 15 years ago.

- While both rules are in widespread clinical use, they have several limitations including either insufficient sensitivity or specificity, the population they were derived on or the number of assessment factors.

- We recently derived and validated a rule suggesting which patients should receive CT for cervical spine injury.

- In the initial validation, the rule had $100 \%$ sensitivity for detecting a cervical spine injury and $65.6 \%$ specificity.

What this study adds

- In this prospective study conducted in two centres in Japan, we validated a previous decision rule that used GCS, cervical tenderness, neurological deficit and mechanism to predict the need for CT.

- Our previous clinical decision rule showed lower sensitivity in this study cohort, and thus we have refined the rule that gave higher sensitivity with little cost to specificity.

- Prospective validation of the new rule in a different cohort is needed before application in real practice.

sequelae, several clinical decision rules have been developed for this pathology. The National Emergency X-Radiography Utilisation Study low-risk criteria (NEXUS) assesses five factors and was the first decision rule developed for all patients with head or neck injuries to be validated with high sensitivity. ${ }^{4}$ The Canadian C-spine rule (CCR) has also been shown to have high sensitivity. ${ }^{5}$ Ottawa researchers compared the CCR and NEXUS using a prospective cohort of alert and stable patients, concluding that the CCR offered significantly higher sensitivity (99.4\% vs $90.7 \%)$ and specificity (45.1\% vs $36.8 \%){ }^{6}$ However, researchers in the USA found that the CCR was unsuitable for determining which patients should be transported to Level 1 trauma centres because of the extremely low specificity $(0.6 \%)^{7}$ 
Cervical plain radiography has now been shown to be inferior to cervical CT from the perspectives of both sensitivity and specificity. ${ }^{8-10}$ As a result, a recent guideline recommended cervical CT as the first-line modality for detecting CSI. ${ }^{11}$ Nowadays, CT can be performed in EDs, but indiscriminate use of CT leads to unnecessary radiological exposure, and clinical decision rules for CT thus need to be validated and applied. Although one study addressed the derivation of a clinical decision rule exclusively for cervical CT, the researchers concluded that the new criteria lacked specificity and more narrow criteria should be validated in an effort to limit the number of cervical spine CTs being performed. ${ }^{12}$

We previously conducted a retrospective study in a single Japanese institution with the aim of deriving a clinical decision rule for determining the need for cervical CT in patients with head or neck trauma (Rule 1). According to that study, cervical spine CT was recommended for patients with (1) GCS score <14; (2) posterior cervical tenderness or neurological deficit, and GCS score $14-15$; (3) age $\geq 60$ years who have fallen down stairs; or (4) age $<60$ who have been injured in a motorcycle collision or fallen from height. Rule 1 was retrospectively validated in a separate cohort from the same institution. ${ }^{13}$ Validation of this previously developed clinical decision rule in a multicentre study is essential before introduction to clinical practice.

The present dual-centre prospective study was therefore conducted as part of the Emergency Medicine, Registry Analysis, Learning and Diagnosis project, which is aimed at minimising life-threatening diseases and injuries currently being overlooked at EDs in Japan. We hypothesised that Rule 1 offers clinically acceptable specificity while not compromising sensitivity in detecting CSI. We planned to derive a refined rule on this cohort if the validation did not show the same accuracy as in our previous study.

\section{METHODS}

\section{Study design}

We performed a prospective observational study in the EDs of two Japanese academic hospitals located in urban areas of Tokyo and Shizuoka prefecture, with annual ambulance census figures of about 12000 and 8000 each, respectively. Both participating hospitals have 64-row, multidetector row CT scanners. The study period was between September 2012 and March 2014. The research ethics boards at each hospital approved the study protocol, which was designed in accordance with the guideline described by Green et al. ${ }^{14}$ One institutional board required written informed consent from every participant, while this requirement was waived by the other institution. This study was registered to the University hospital Medical Information Network (UMIN) centre website (ID: UMIN000011283).

\section{Study population}

We enrolled patients with head or neck trauma who were over 16 years old and brought to the participating hospital by ambulance. Patients with polytrauma were included, but those with penetrating neck injury were excluded.

\section{Study protocol}

\section{Methods and measurements}

Clinical information such as age, sex, GCS score, alcohol intake and mechanism of injury were collected. Alcohol use was defined as clinical intoxication. Mechanisms of injury were described as follows: ground-level fall, fall down stairs, fall from height (defined as fall from $\geq 3 \mathrm{~m}$ ), pedestrian struck, bicycle collision, motorcycle collision, motor vehicle collision, hanging and other. Mechanisms of injury were recorded in medical records in a standardised manner.

Level of consciousness, neck pain and neurological deficit were assessed by physicians on arrival at hospital. When neurological deficit due to cervical spinal cord injury was found, the emergency physician classified the severity as Frankel grade A, B, C or D. ${ }^{15}$

The electronic charts contain a template for all the fields we abstract. Investigators manually transferred data from electronic charts into a computer database using FileMaker Pro V.12 software (FileMaker, Santa Clara, California, USA).

In both EDs, cervical CT was considered the first-line modality in diagnosing CSI. Cervical CT indications were decided based on the assessment of the attending physician. Physicians were aware of Rule 1 and could have used it if they chose to help guide decisions. Physicians could choose cervical plain radiography they considered this modality as suitable for the patient.

For this study, a CSI was considered present if a fracture or dislocation was identified on CT. All CT data were read by both emergency physicians and certified radiologists, and radiological findings were assessed.

Patients who did not undergo cervical CT were followed for 14 days, during hospitalisation, as an outpatient or by telephone interview. When new cervical tenderness or neurological deficits that were possibly attributable to cervical spine injury were identified, the patient was re-assessed by emergency physicians and sent for radiological assessment as appropriate.

\section{Outcomes}

The objectives of this study were to prospectively assess the accuracy and reliability of Rule 1 in detecting CSI among patients with head or neck trauma and potential for rule refinement. Prospective validation of a new clinical decision rule should be optimally done prior to its use for patient care.

\section{Data analysis}

To assess the validity of Rule 1 , sensitivity and specificity with 95\% CIs were calculated. The a priori sample size was estimated to be 2000 patients with head or neck trauma, expected to include 80 CSI cases, based on the desired precision of $95 \%$ sensitivity for CSI with a $95 \%$ CI of $\pm 5 \%$.

If Rule 1 did not achieve satisfactory sensitivity and specificity, a new clinical decision rule was generated using recursive partitioning analysis, which is considered appropriate when the objective of the study is to develop a decision rule with very high sensitivity. ${ }^{14} 16$ Variables were selected by considering clinical feasibility. We estimated that a clinical decision rule to detect an injury with the possibility of causing severe disability needs its sensitivity close to $100 \%$ with a narrow CI. Based on this philosophy, we selected the practical new rule offering the highest sensitivity. As well as Rule 1, performance of the new rule was assessed by calculating its sensitivity and specificity with 95\% CIs. We excluded all data from any participant with unconfirmed outcome variable.

Data analysis and recursive partitioning were done using JMP V.10.0 statistical software (SAS Institute, Cary, North Carolina, USA).

\section{RESULTS}

Among the total of 3027 patients with head or neck trauma screened, 1192 were enrolled while 1835 without informed consent were not. Another 265 discharged patients were 


\section{3,027 patients eligible}

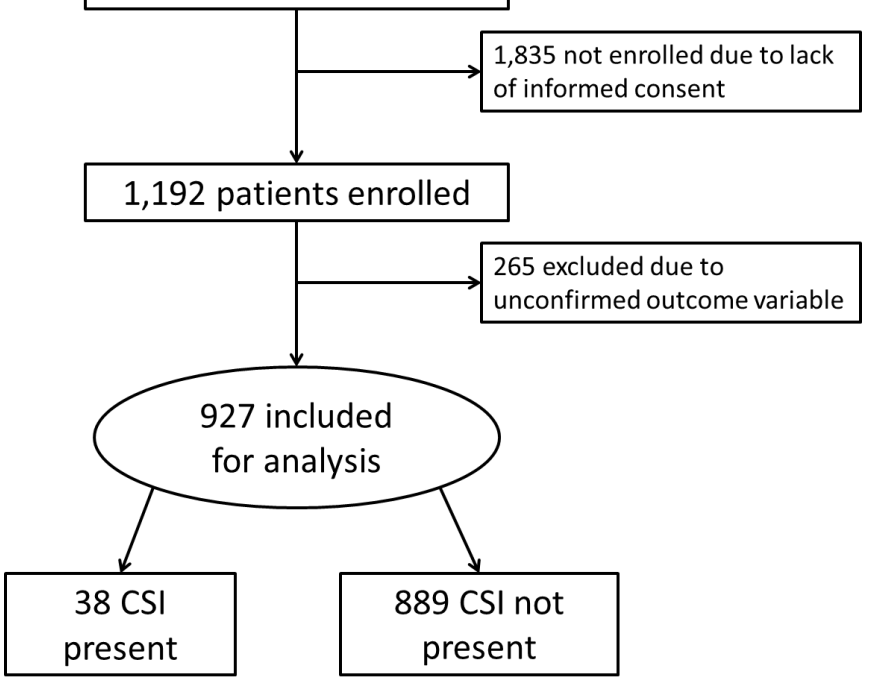

Figure 1 Details of enrolment and flow of patients in the study. CSI, cervical spine injury.

excluded because they did not undergo CT imaging or could not be followed up. Finally, 927 who had either a CT or complete follow-up were included for analysis (figure 1). Median age was 59 years (IQR, $36-75$ years) and $63.3 \%$ were men. About a quarter of patients were determined clinically to be affected by alcohol. Patients with GCS scores of 15,14 and $<14$ represented $77.9 \%, 15.7 \%$ and $6.4 \%$ of the population, respectively. Patient characteristics are shown in table 1.

We compared the characteristics of patients not enrolled with those enrolled (table 2). The non-enrolled patients tended to be slightly younger, to include a greater proportion of men and to have a greater intake of alcohol.

Cervical CT was performed in $63.0 \%$ of all enrolled patients, and CSI was detected in 38 patients.

The sensitivity and specificity of Rule 1 in detecting CSI among patients with head or neck trauma were $92.1 \%$ (95\% CI $79.2 \%$ to $97.3 \%$ ) and $58.6 \%$ (95\% CI $55.4 \%$ to $61.9 \%)$, respectively (table 3 ).

Because Rule 1 failed to achieve $100 \%$ sensitivity in this validation set, we performed recursive partitioning to modify Rule 1 to provide higher sensitivity. A new rule, Rule 2, was derived in which cervical CT was indicated for those with GCS score $<14$, cervical tenderness, neurological deficit or specific injury mechanisms of falling down stairs, motorcycle collision or fall from height (figures 2 and 3 ). This new rule successfully maintained $100 \%$ sensitivity in this dataset. Sensitivity and specificity were $100 \%(95 \%$ CI $90.8 \%$ to $100 \%)$ and $51.9 \%$ (95\% CI $48.6 \%$ to $55.2 \%$ ), respectively (table 3 ).

\section{DISCUSSION}

Neither of the current rules is perfect; NEXUS has been based on positive findings on plain X-ray, while CCR is also limited by age and consciousness level restrictions as well as its complicated algorithm. Since the Eastern Association for the Surgery of Trauma guideline recommended CT as a first-line modality, the number of CT examinations and thus the amount of radiological exposure has certainly increased in emergency medicine settings.

We conducted this research to assess Rule 1 with the aim of confirming clinically acceptable specificity without compromising sensitivity. Because Rule 1 could not maintain 100\%
Table 1 Background characteristics of patients

\begin{tabular}{|c|c|c|c|}
\hline & Male & Female & Male and female \\
\hline Characteristic & $(n=587)$ & $(n=340)$ & $(n=927)$ \\
\hline $\begin{array}{l}\text { Age, years—median } \\
\text { (IQR) }\end{array}$ & $56(36-71)$ & $65.5(35.25-79)$ & $59(36-75)$ \\
\hline $\begin{array}{l}\text { Transported by } \\
\text { ambulance- } n(\%)\end{array}$ & $587(100)$ & $340(100)$ & $927(100)$ \\
\hline Alcohol—n/total n (\%) & $198 / 580(34.1)$ & $54 / 338(16.0)$ & $157 / 918(27.5)$ \\
\hline $\begin{array}{l}\text { Posterior cervical } \\
\text { tenderness—n/total } \\
\mathrm{n}(\%)\end{array}$ & 96/565 (17.0) & $61 / 327(18.7)$ & 157/892 (17.6) \\
\hline $\begin{array}{l}\text { Neurological deficit-n/ } \\
\text { total } n(\%)\end{array}$ & $68 / 582(11.7)$ & 30/337 (8.9) & 98/919 (10.7) \\
\hline \multicolumn{4}{|l|}{ GCS score—n/total n (\%) } \\
\hline $14-15$ & $547 / 586(93.3)$ & $319 / 340$ (93.8) & $866 / 926(93.5)$ \\
\hline $9-13$ & $37 / 586(6.3)$ & $18 / 340(5.3)$ & $55 / 926(5.9)$ \\
\hline $3-8$ & $2 / 586(0.3)$ & $3 / 340(0.9)$ & $5 / 926(0.5)$ \\
\hline \multicolumn{4}{|c|}{ Mechanisms of injury—n/total n (\%) } \\
\hline Ground-level fall & $217 / 587(37.0)$ & $162 / 339(47.8)$ & $379 / 926(40.9)$ \\
\hline Fall down stairs & $117 / 587(20.0)$ & $56 / 339(16.5)$ & $173 / 926(18.7)$ \\
\hline $\begin{array}{l}\text { Motor vehicle } \\
\text { collision }\end{array}$ & $55 / 587(9.4)$ & $38 / 339(11.2)$ & $93 / 926(10.0)$ \\
\hline Bicycle collision & $52 / 587(8.9)$ & $31 / 339(9.1)$ & $83 / 926(9.0)$ \\
\hline Motorcycle collision & $66 / 587(11.2)$ & $14 / 339(4.1)$ & $80 / 926(8.6)$ \\
\hline Assault & $34 / 587(5.8)$ & $8 / 339(2.4)$ & $42 / 926(4.5)$ \\
\hline Struck as pedestrian & $14 / 587(2.4)$ & 19/339 (5.6) & $33 / 926(3.5)$ \\
\hline Fall from height* & 9/587 (1.5) & 2/339 (0.6) & $11 / 926(1.2)$ \\
\hline Hanging & $0 / 587(0)$ & $2 / 339(0.6)$ & $2 / 926(0.2)$ \\
\hline Fall onto head & $1 / 587(0.2)$ & $0 / 339(0)$ & $1 / 926(0.1)$ \\
\hline Other & $22 / 587(3.7)$ & $7 / 339(2.1)$ & $29 / 926(3.1)$ \\
\hline CT performed-n (\%) & $393(67.0)$ & $191(56.2)$ & $584(63.0)$ \\
\hline $\begin{array}{l}\text { Cervical spine injury—n } \\
(\%)\end{array}$ & $33 / 587(5.6)$ & $5 / 340(1.5)$ & $38(4.1)$ \\
\hline
\end{tabular}

Alcohol use, posterior cervical tenderness, neurological deficit, GCS score and mechanisms of injury were not obtained for all enrolled patients due to missing data.

${ }^{*}$ Fall from height $\geq 3 \mathrm{~m}$.

sensitivity in this prospective study, we derived Rule 2 as a new clinical decision rule for cervical CT in patients with head or neck trauma. The rule had a $100 \%$ sensitivity $(95 \%$ CI $90.8 \%$ to $100 \%)$ and specificity of $51.9 \%$ (95\% CI $48.6 \%$ to $55.2 \%)$. In our study, emergency physicians decided to perform CT for

Table 2 Background characteristics according to study enrolment

\begin{tabular}{|c|c|c|c|}
\hline & Included & Excluded & Not enrolled \\
\hline & $(n=927)$ & $(n=265)$ & $(n=1835)$ \\
\hline $\begin{array}{l}\text { Age, years-median } \\
\text { (IQR) }\end{array}$ & $59(36-75)$ & $52(32-71)$ & $51(32-72)$ \\
\hline Sex, male-n (\%) & $587(63.3)$ & $167(63.0)$ & $1241(67.6)$ \\
\hline Alcohol一n/total n (\%) & $157 / 918(27.5)$ & $104 / 263(39.5)$ & $709 / 1827(38.8)$ \\
\hline $\begin{array}{l}\text { Posterior cervical } \\
\text { tenderness—n/total } \\
\mathrm{n}(\%)\end{array}$ & $157 / 892(17.6)$ & $10 / 256(3.9)$ & $154 / 1696(9.0)$ \\
\hline $\begin{array}{l}\text { Neurological } \\
\text { deficit—n/total n (\%) }\end{array}$ & 98/919 (10.7) & $0 / 265(0)$ & $0 / 1785(0)$ \\
\hline \multicolumn{4}{|l|}{ GCS score-n/total n (\%) } \\
\hline $14-15$ & $866 / 926$ (93.5) & $257 / 265(97.0)$ & $1621 / 1835(88.3)$ \\
\hline $9-13$ & $55 / 926(5.9)$ & $8 / 265(3.0)$ & $178 / 1835(9.7)$ \\
\hline $3-8$ & $5 / 926(0.5)$ & $0 / 265(0)$ & $36 / 1835(1.9)$ \\
\hline
\end{tabular}




\begin{tabular}{|c|c|c|}
\hline & Rule 1 & Rule 2 \\
\hline \multicolumn{3}{|l|}{ Positive, $n$} \\
\hline CSI & 35 & 38 \\
\hline Non-CSI & 364 & 424 \\
\hline \multicolumn{3}{|l|}{ Negative, $\mathrm{n}$} \\
\hline CSI & 3 & 0 \\
\hline Non-CSI & 517 & 457 \\
\hline Sensitivity, \% ( $95 \% \mathrm{Cl})$ & 92.1 (79.2 to 97.3$)$ & 100 (90.8 to 100$)$ \\
\hline Specificity, \% (95\% Cl) & 58.6 (55.4 to 61.9$)$ & 51.9 (48.6 to 55.2$)$ \\
\hline $\begin{array}{l}\text { Negative predictive value, } \\
\%\end{array}$ & 99.4 & 100 \\
\hline
\end{tabular}

CSI, cervical spine injury.

$63.0 \%(584 / 927)$ of patients with head or neck trauma transported by ambulance, finding CSI in 6.5\% (38/584). Rule 2, with $51.9 \%$ specificity, could have contributed to reducing the number of patients who underwent CT by more than $10 \%$.

Our rule significantly differs from CCR and NEXUS in allowing the presence or absence of cervical tenderness or neurological deficit in patients with a GCS score of 14 as well as 15 to guide imaging decisions. We believe that patients with a GCS score of 14 can be assessed reliably and physicians usually apply this approach in clinical settings. Our opinion has been supported by other researchers performing physical assessments in trauma patients with GCS scores of 14 and $15 .{ }^{17}{ }^{18}$ If our rule had indicated cervical CT for all patients with GCS scores less than 15 , the specificity of Rule 2 would have decreased substantially.

\section{9 patients, 38 had CSI}

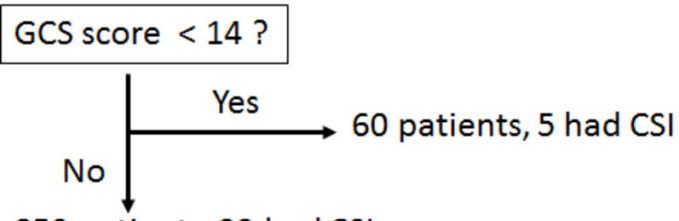

859 patients, 33 had CSI

Cervical tenderness ?

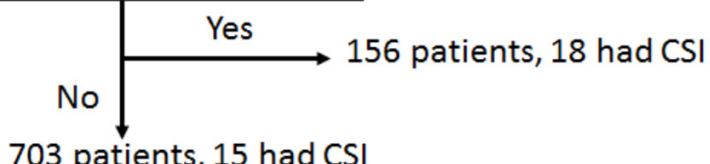

703 patients, 15 had CSI

Neurological deficit?

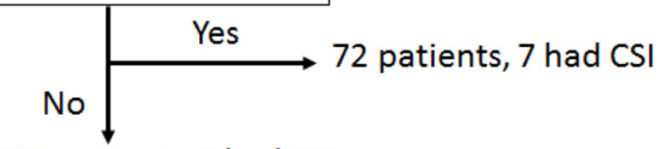

631 patients, 8 had CSI

Any of 3 injury mechanisms?

(Fall down stairs, motorcycle collision, fall from height)

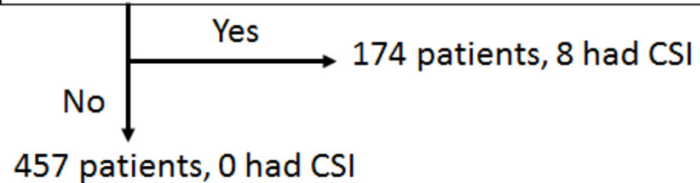

\section{7 patients, 0 had CSI}

Figure 2 Example of recursive partitioning analysis with Rule 2. CSI, cervical spine injury.

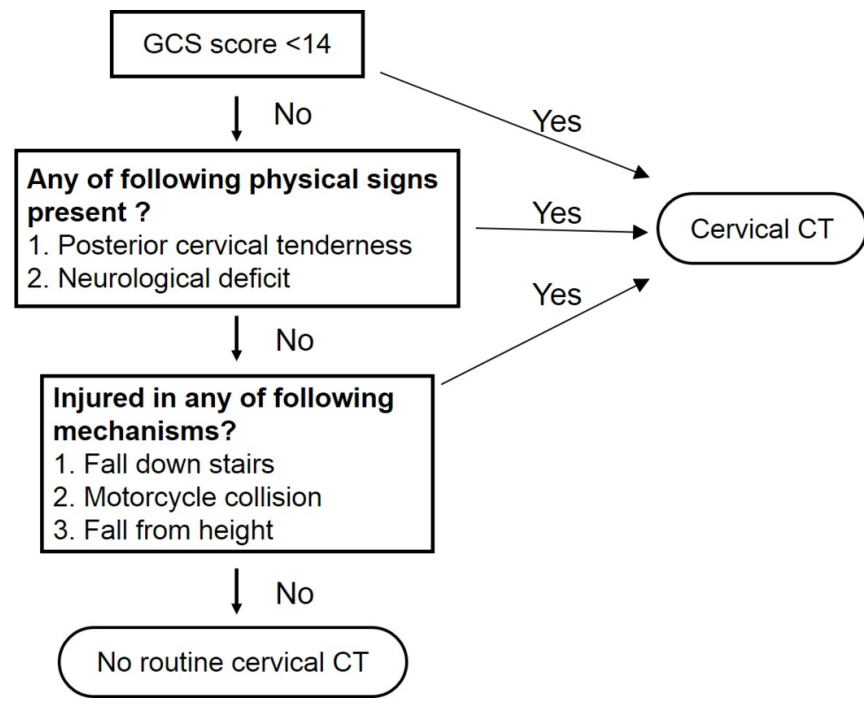

Figure 3 Novel clinical decision rule for cervical CT in patients with head or neck trauma (Rule 2). This rule was developed by the present study. This rule recommends cervical CT if 'yes' was answered to any of three boxes. Fall from height $\geq 3 \mathrm{~m}$.

Compared with the CCR and NEXUS, our Rule 2 offers several benefits. First, Rule 2 allows more patients to be included, as a GCS of 14 is permissible for clinical decision-making. The issue of distracting injuries is not present. The rule uses a small number of factors for assessment during application of the clinical decision rule. Compared with the CCR and NEXUS, it offers the additional strength that each component of the rule comes in similar order to the regular assessment of trauma patients in an ED; starting with level of consciousness, then physical signs, and finally evaluating the mechanism of injury.

The study design did not enable us to apply the CCR to our cohort, and because we did not measure distracting injuries in patients, application of the full NEXUS was not feasible.

However, Rule 2 appears to have a specificity (51.9\%) that is equal or better than that of the other rules. Of course, further prospective validation with a larger cohort is needed to confirm these findings.

\section{LIMITATIONS}

First, our initial sample size analysis required 2000 patients, but we only enrolled 1192 because of difficulty in obtaining informed consent at crowded EDs. We could not follow up 265 of enrolled patients who did not undergo CT. Comparing the characteristics of those excluded and those not enrolled with those finally included for analysis (table 2), excluded patients and those not enrolled tended to be younger, to include more men and to have a greater intake of alcohol. Posterior cervical tenderness and neurological deficit were less frequent than among the included, so probability of potential CSI among those excluded or not enrolled was considered low. Although our study results are not free from selection bias due to the low enrolment rate, we do not believe that the sensitivity and specificity of Rule 2 would have been markedly influenced if we had succeeded in including all 265 patients without successful follow-up and 1835 without consent.

Second, we were unable to recruit the total number of patients estimated by our sample size, and thus the number of patients with CSI was low. This led to wider CIs than we would like, with the lower limit for sensitivity of Rule $290.8 \%$. This new 
rule needs to be validated in a larger cohort to have sufficient statistical power.

Third, not all enrolled patients underwent cervical CT. Because Japanese emergency physicians sometimes withhold cervical CT in head or neck trauma in patients at low risk of CSI, mandating diagnostic imaging for every patient would have been unethical. We followed patients who did not undergo CT either by telephone interview or as outpatients.

Fourth, we did not assess interobserver agreement among more than two physicians for the clinical variables used to derive clinical decision rules. The research group at the University of Ottawa revealed a small level of interobserver disagreement among variables such as neurological deficit, posterior cervical tenderness and mechanisms of injury. ${ }^{5}$ We considered the clinical variables we selected as sufficiently reliable to be used in a clinical decision rule.

Fifth, we assessed the rule in two centres in the same country. The proposed rule needs to be externally validated in a different cohort, and another country, before being fully incorporated into clinical practice.

\section{CONCLUSIONS}

We have refined a previously validated decision rule to suggest which patients with head or neck injuries require CT scan. 'Rule 2' seems to offer a more suitable clinical decision rule than the original rule. Further prospective validation of Rule 2 in a larger cohort is needed before our new rule can be applied in real practice.

Correction notice This article has been corrected after it was published Online First. The funding statement has been amended.

Contributors $\mathrm{TI}$ and AK conceived the study, designed the trial and obtained research funding. AK and ST supervised the conduct of the trial and data collection. $\mathrm{TI}$ and GM undertook recruitment of participating centres and patients and managed the data, including quality control. TI, AK and NT provided statistical advice on study design and analysed the data. TI drafted the manuscript, and all authors contributed substantially to its revision. TI takes responsibility for the paper as a whole.

Funding National Center for Global Health and Medicine (grant no. 24-116, 26A201, 29-2001)

Disclaimer The funding source played no role in the collection, analysis or interpretation of data, the writing of the report or the decision to publish.

Competing interests None declared.

Patient consent Not required.

Ethics approval National Center for Global Health and Medicine.

Provenance and peer review Not commissioned; externally peer reviewed.

Data sharing statement No additional data are available.
Open access This is an open access article distributed in accordance with the Creative Commons Attribution Non Commercial (CC BY-NC 4.0) license, which permits others to distribute, remix, adapt, build upon this work non-commercially, and license their derivative works on different terms, provided the original work is properly cited, appropriate credit is given, any changes made indicated, and the use is non-commercial. See:http://creativecommons.org/licenses/by-nc/4.0/.

\section{REFERENCES}

1 Grossman MD, Reilly PM, Gillett T, et al. National survey of the incidence of cervical spine injury and approach to cervical spine clearance in U.S. trauma centers. J Trauma 1999:47:684-90.

2 Holly LT, Kelly DF, Counelis GJ, et al. Cervical spine trauma associated with moderate and severe head injury: incidence, risk factors, and injury characteristics. J Neurosurg 2002;96:285-91.

3 Duane TM, Dechert T, Wolfe LG, et al. Clinical examination and its reliability in identifying cervical spine fractures. J Trauma 2007;62:1405-10.

4 Hoffman JR, Mower WR, Wolfson AB, et al. Validity of a set of clinical criteria to rule out injury to the cervical spine in patients with blunt trauma. N Engl J Med Overseas Ed 2000;343:94-9.

5 Stiell IG, Wells GA, Vandemheen KL, et al. The Canadian C-spine rule for radiography in alert and stable trauma patients. JAMA 2001;286:1841-8.

6 Stiell IG, Clement CM, McKnight RD, et al. The Canadian C-spine rule versus the NEXUS low-risk criteria in patients with trauma. N Engl J Med 2003;349:2510-8.

7 Duane TM, Wilson SP, Mayglothling J, et al. Canadian cervical spine rule compared with computed tomography: a prospective analysis. J Trauma 2011;71:352-7.

8 Diaz JJ, Gillman C, Morris JA, et al. Are five-view plain films of the cervical spine unreliable? A prospective evaluation in blunt trauma patients with altered mental status. J Trauma 2003;55:658-64.

9 Holmes JF, Akkinepalli R. Computed tomography versus plain radiography to screen for cervical spine injury: a meta-analysis. J Trauma 2005;58:902-5.

10 Mathen $\mathrm{R}$, Inaba K, Munera F, et al. Prospective evaluation of multislice computed tomography versus plain radiographic cervical spine clearance in trauma patients. J Trauma 2007:62:1427-31.

11 Como JJ, Diaz JJ, Dunham CM, et al. Practice management guidelines for identification of cervical spine injuries following trauma: update from the eastern association for the surgery of trauma practice management guidelines committee. J Trauma 2009:67:651-9.

12 Duane TM, Young A, Mayglothling J, et al. CT for all or selective approach? Who really needs a cervical spine CT after blunt trauma. J Trauma Acute Care Surg 2013;74:1098-101.

13 Inagaki T, Kimura A, Hagiwara A, et al. A clinical decision rule for cervical spine CT in head or neck trauma patients. Nihon Kyukyu Igakukai Zasshi 2013;24:192-9.

14 Green SM, Schriger DL, Yealy DM. Methodologic standards for interpreting clinical decision rules in emergency medicine: 2014 update. Ann Emerg Med 2014;64:286-91.

15 Frankel $\mathrm{HL}$, Hancock DO, Hyslop G, et al. The value of postural reduction in the initial management of closed injuries of the spine with paraplegia and tetraplegia. I. Paraplegia 1969:7:179-92.

16 Stiell IG, Wells GA. Methodologic standards for the development of clinical decision rules in emergency medicine. Ann Emerg Med 1999;33:437-47.

17 Rostas J, Cason B, Simmons J, et al. The validity of abdominal examination in blunt trauma patients with distracting injuries. J Trauma Acute Care Surg 2015:78:1095-101.

18 Rose MK, Rosal LM, Gonzalez RP, et al. Clinical clearance of the cervical spine in patients with distracting injuries: it is time to dispel the myth. J Trauma Acute Care Surg 2012;73:498-502. 